\title{
Serum testosterone levels may influence body composition and cardiometabolic health in men with spinal cord injury
}

\author{
Sally M. Abilmona ${ }^{1} \cdot$ Ryan M. Sumrell ${ }^{1}$ Ranjodh S. Gill2,3 ${ }^{2, ~ R o b e r t ~ A . ~ A d l e r ~}{ }^{2,3} \cdot$ Ashraf S. Gorgey $\mathbb{1}^{1,4}$
}

Received: 17 May 2018 / Revised: 20 September 2018 / Accepted: 1 October 2018 / Published online: 22 October 2018

(c) International Spinal Cord Society 2018

\begin{abstract}
Study design Cross-sectional study.

Objective To establish the association between serum testosterone (T) levels, biomarkers of cardiometabolic health and regional body composition variables after spinal cord injury (SCI).

Setting Medical research center.

Methods Metabolic and body composition measurements were collected from thirty-six men with chronic motor complete SCI. Serum T, carbohydrate, and lipid profiles were measured after an overnight fast. Body composition was measured using anthropometrics, dual-energy X-ray absorptiometry, and magnetic resonance imaging. Participants were evenly classified into tertiles based on their serum $\mathrm{T}$ levels into low, mid-normal and normal ranges.

Results Low, mid-normal, and normal range serum T were $288.8 \pm 84.9 \mathrm{ng} / \mathrm{dL}, 461.0 \pm 52.5 \mathrm{ng} / \mathrm{dL}$ and $648.0 \pm 53.5 \mathrm{ng} / \mathrm{dL}$, respectively. Low range serum $\mathrm{T}$ group had greater total $(9.6 \%, P=0.04)$ percentage fat mass and visceral adipose tissue (VAT) area $(72 \%, P=0.01)$ compared to normal range serum $\mathrm{T}$ group. Serum $\mathrm{T}$ was related to the absolute whole thigh muscle area $(r=0.40, P<0.05)$ after controlling for body mass index. Serum $\mathrm{T}$ was negatively related to fasting plasma glucose $(r=-0.46, P=0.006)$ and insulin $(r=-0.42, P=0.01)$, HbAlc $(r=-0.39, P=0.02)$ and triglycerides $(r=$ $-0.36, P=0.03)$.

Conclusion Men with low serum $\mathrm{T}$ have more unfavorable body composition and cardiometabolic health outcomes after SCI. Testosterone replacement therapy may serve as a potential strategy in preventing cardiometabolic disorders after SCI.
\end{abstract}

\section{Introduction}

Spinal cord injury (SCI) leads to dramatic changes in body composition and metabolic profile, which represents an accelerated form of aging [1]. Inactivity below the level of injury contributes up to $50 \%$ of the rapid lean muscle mass atrophy observed following SCI [2], which may lead to

Ashraf S. Gorgey

ashraf.gorgey@va.gov

1 Spinal Cord Injury and Disorders, Hunter Holmes McGuire VA Medical Center, Richmond, VA, USA

2 Endocrinology Section, Hunter Holmes McGuire VA Medical Center, Richmond, VA, USA

3 Endocrine Division, Virginia Commonwealth University, Richmond, VA, USA

4 Department of Physical Medicine and Rehabilitation, Virginia Commonwealth University, Richmond, VA, USA other serious health consequences. A dramatic loss in skeletal muscle and increased adiposity often lead to adverse effects on various aspects of cardiometabolic health. Previous work has shown that individuals with SCI have up to $58 \%$ greater visceral adipose tissue (VAT) compared to weight and waist circumference (WC) matched able-bodied controls [3]. Increase in VAT is associated with increase in inflammatory biomarkers after SCI [4]. The dramatic changes in body composition and cardiometabolic variables often develop into costly chronic diseases such as metabolic syndrome, type 2 diabetes mellitus, and cardiovascular disease $[1,5]$.

Testosterone (T) is widely recognized as the primary male sex hormone. Its anabolic effects contribute to increased muscle mass, improved bone mineral density, and musculoskeletal strength. As men age, they often experience lateonset hypogonadism characterized by low serum $\mathrm{T}$ production [6]. In fact, $60 \%$ of men above the age of 65 have low serum $\mathrm{T}$ levels accompanied with sarcopenia and osteoporosis $[7,8]$. It is difficult to discern the etiology of 
these symptoms due to the significant reduction in physical activity that accompanies aging [9]. Moreover, the decrease in muscle mass and increase in fat mass that accompanies aging may be linked to a decrease in serum T levels [10]. Men with SCI experience similar body composition changes at a younger age which may be influenced by low serum $\mathrm{T}$ levels in aging able-bodied men. In fact, forty to sixty percent of men with SCI have low serum T levels ( $<325 \mathrm{ng} / \mathrm{dL})$ [11]. This phenomenon has been previously described as pre-mature aging in men with SCI [1]. The inherent decrease in physical activity following SCI may serve as a representative model for studying the association between serum $\mathrm{T}$ and body composition. Barbonetti et al. noted that $35 \%$ of men with SCI have serum T levels below $300 \mathrm{ng} / \mathrm{dL}$, with a moderate to strong relationship with leisure-time physical activity (LTPA). Those with $7.6 \mathrm{~h}$ per week or more of LTPA and body mass index (BMI) less than $25.6 \mathrm{~kg} / \mathrm{m}^{2}$ had serum $\mathrm{T}$ above $300 \mathrm{ng} / \mathrm{dL}$. However, participants with different American Spinal Injury Association (ASIA) Impairment Scale (AIS) classification A-D were included, which might have confounded the relationship between serum $\mathrm{T}$ and level of physical activity [12]. It is well established that men with motor complete SCI are considered the lowest on the spectrum of physical activity [5]. Therefore, studying those with motor complete SCI may reflect the accurate association between serum $\mathrm{T}$ and cardiometabolic risk factors independent of the level of physical activity.

Previous studies have investigated the association between serum $\mathrm{T}$ levels and body composition [13] as well as biomarkers of cardiometabolic health [12, 13] in men with SCI and able-bodied men [14]. However, regional body composition assessments were not captured to examine the association of serum $\mathrm{T}$ levels with total and regional lean mass, thigh skeletal muscle cross-sectional area (CSA), intramuscular fat (IMF), and VAT [15, 16]. Regional body composition changes have been strongly associated with cardiometabolic risk factors in persons with SCI [17]. Moreover, ectopic adiposity has been linked with impaired glucose tolerance, insulin resistance, and production of inflammatory cytokines [3-5]. Considering the escalating prevalence of cardiovascular disorders after SCI, establishing the role of serum $\mathrm{T}$ on regional and whole body composition as well as cardiometabolic variables is of paramount significance to this population prior to proceeding with long-term intervention. Moreover, it will provide credence to the hypothesis that serum $\mathrm{T}$ may exert a homeostatic balance between body composition and metabolic health variables independent of the level of physical activity in men with motor complete SCI. Therefore, the purpose of the current work was to determine whether serum $\mathrm{T}$ levels may be correlated with changes in total and regional body composition profiles, with special interest on muscle size and ectopic adiposity (IMF and VAT) as well as biomarkers of cardiometabolic health in men with motor complete SCI.

\section{Methods}

\section{Participants}

Thirty-six men with chronic ( $>1$-year post-injury) motor complete SCI [C5-T11, AIS A or B] participated in one of two clinical trials (NCT01652040 and NCT02660073). Participants were recruited within the greater Richmond area through study flyers, word of mouth and referral by SCI physicians. The ages ranged from 18 to 65 years, and the mean \pm SD for age, height, and weight of the participants were $37 \pm 5$ years, $178 \pm 5 \mathrm{~cm}$ and $74 \pm 14 \mathrm{~kg}$, respectively. The average BMI, time since injury (TSI), and level of injury (LOI) are presented in Table 1. Inclusion and exclusion criteria, along with further details of the clinical trial protocols were previously published [18]. The data in this manuscript are cross-sectional and were analyzed prior to any study intervention. Each participant received and signed an informed consent that was approved by a local ethics committee. All aspects of the study procedures were conducted according to the declaration of Helsinki.

\section{Body composition}

\section{Body weight and height}

A wheelchair scale (Tanita, Arlington Heights, IL) was used to weigh participants. To measure height, the participants were in a supine position. To ensure ankle dorsiflexion, a board was placed at the soles of the feet. Height was measured using a Harpenden Stadiometer to the nearest 0.1 $\mathrm{cm}$. BMI $\left(\mathrm{kg} / \mathrm{m}^{2}\right)$ was then calculated as weight $(\mathrm{kg})$ divided by height $\left(\mathrm{m}^{2}\right)$.

\section{Anthropometrics}

Waist (narrowest region below the ribcage) and abdominal (widest region at the level of umbilicus) circumferences were performed in a lying and seated positions wearing non-restrictive clothes. Participants were instructed to take a deep breath and then exhale to capture measurements during the expiration phase. Measurements were reported to the nearest $0.1 \mathrm{~cm}$ and repeated until three data points were within $0.5 \mathrm{~cm}$ range of one another.

\section{Dual-energy X-ray absorptiometry}

Dual-energy X-ray absorptiometry (DXA) was used to assess body composition, including fat mass, lean mass, and 
Table 1 Participants' physical characteristics, anthropometrics, MRI, and DXA outcomes separated based on tertile classifications of the level of serum testosterone

\begin{tabular}{|c|c|c|c|}
\hline & $\begin{array}{l}\text { Low range testosterone } \\
(\leq 400 \mathrm{ng} / \mathrm{dL}) \\
(n=12)\end{array}$ & $\begin{array}{l}\text { Mid-Normal range } \\
\text { testosterone }(401-544 \mathrm{ng} / \mathrm{dL}) \\
(n=12)\end{array}$ & $\begin{array}{l}\text { Normal range testosterone } \\
(\geq 555 \mathrm{ng} / \mathrm{dL}) \\
(n=12)\end{array}$ \\
\hline \multicolumn{4}{|c|}{ Physical characteristics } \\
\hline Age (years) & $40 \pm 12$ & $36 \pm 10$ & $34 \pm 10$ \\
\hline Weight (kg) & $78.9 \pm 10.3$ & $74.7 \pm 18.7$ & $68.1 \pm 11.4$ \\
\hline Height (cm) & $177.4 \pm 5.8$ & $180.1 \pm 4.8$ & $178.0 \pm 5.1$ \\
\hline BMI & $25.6 \pm 3.8$ & $23.0 \pm 5.6$ & $21.5 \pm 3.2^{*}$ \\
\hline TSI (years) & $12 \pm 11$ & $8 \pm 9$ & $8 \pm 8$ \\
\hline LOI (range) & C5-L1 & $\mathrm{C} 5-\mathrm{T} 10$ & $\mathrm{C} 7-\mathrm{T} 12$ \\
\hline \multicolumn{4}{|c|}{ Anthropometric Measurements } \\
\hline $\begin{array}{l}\text { Supine waist } \\
\text { circumference }(\mathrm{cm})\end{array}$ & $87.5 \pm 10.5$ & $84.2 \pm 14.4$ & $74.7 \pm 8.1^{*}$ \\
\hline $\begin{array}{l}\text { Seated waist } \\
\text { circumference }(\mathrm{cm})\end{array}$ & $92.4 \pm 9.1$ & $87.9 \pm 11.9$ & $81.5 \pm 8.8^{*}$ \\
\hline $\begin{array}{l}\text { Supine abdominal } \\
\text { circumference }(\mathrm{cm})\end{array}$ & $89.8 \pm 11.1$ & $85.5 \pm 17.2$ & $74.5 \pm 8.6^{*}$ \\
\hline $\begin{array}{l}\text { Seated abdominal } \\
\text { circumference }(\mathrm{cm})\end{array}$ & $89.8 \pm 11.1$ & $85.5 \pm 17.2$ & $74.5 \pm 8.6^{*}$ \\
\hline \multicolumn{4}{|l|}{ DXA Outcomes } \\
\hline Region fat (\%) & $33.5 \pm 7.3$ & $30.6 \pm 12.1$ & $23.9 \pm 7.1^{*}$ \\
\hline Fat mass $(\mathrm{g})$ & $26554 \pm 7201$ & $24701 \pm 13752$ & $16750 \pm 7618$ \\
\hline $\begin{array}{l}\text { Lean mass }(\mathrm{g})^{\mathrm{a}} \\
\quad \text { Trunk }\end{array}$ & $49038 \pm 7587$ & $47795 \pm 6768$ & $48553 \pm 6194$ \\
\hline Region Fat (\%) & $37.9 \pm 8.6$ & $32.6 \pm 14.6$ & $25.2 \pm 9.4^{*}$ \\
\hline Fat mass (g) & $15682 \pm 4657$ & $13629 \pm 8857$ & $8650 \pm 4860 *$ \\
\hline $\begin{array}{l}\text { Lean mass }(\mathrm{g}) \\
\quad \text { Legs }\end{array}$ & $23839 \pm 2472$ & $23138 \pm 3946$ & $23038 \pm 2938$ \\
\hline Region fat $(\%)$ & $33.4 \pm 7.6$ & $32.8 \pm 11.2$ & $27.4 \pm 6.6$ \\
\hline Fat mass $(\mathrm{g})$ & $74901 \pm 2427$ & $7799 \pm 4306$ & $5782 \pm 2231$ \\
\hline Lean mass $(\mathrm{g})^{\mathrm{a}}$ & $13238 \pm 2605$ & $13656 \pm 2373$ & $14098 \pm 2162$ \\
\hline \multicolumn{4}{|l|}{ MRI Outcomes } \\
\hline $\operatorname{VAT}_{\mathrm{CSA}}\left(\mathrm{cm}^{2}\right)^{\mathrm{b}}$ & $127.9 \pm 63.7$ & $97.4 \pm 70.5$ & $36.2 \pm 26.3 *$ \\
\hline $\operatorname{SAT}_{\mathrm{CSA}}\left(\mathrm{cm}^{2}\right)^{\mathrm{b}}$ & $143.1 \pm 61.0$ & $158.2 \pm 105.8$ & $102.3 \pm 66.4$ \\
\hline VAT:SAT Ratio ${ }^{\mathrm{b}}$ & $1.0 \pm 0.58$ & $0.65 \pm 0.33$ & $0.46 \pm 0.28 *$ \\
\hline $\begin{array}{l}\text { Absolute Whole } \\
\text { Muscle CSA }{ }^{c}\end{array}$ & $78.6 \pm 24.9$ & $80.9 \pm 15.9$ & $93.3 \pm 16.0$ \\
\hline $\operatorname{IMF}(\%)^{\mathrm{c}}$ & $17.2 \pm 11.0$ & $13.6 \pm 9.0$ & $7.8 \pm 6.1$ \\
\hline
\end{tabular}

According to the American Endocrine Society, hypogonadism is defined as testosterone level below $300 \mathrm{ng} /$ $\mathrm{dL}$, but to evenly stratify our data, we separated groups into evenly dispersed tertiles. Data are presented as mean $\pm \mathrm{SD}$

$B M I$ body mass index, $C S A$ cross-sectional area, $D X A$ dual-energy $\mathrm{X}$-ray absorptiometry, IMF intramuscular fat, $L O I$ level of injury, MRI magnetic resonance imaging, $S A T_{C S A}$ subcutaneous adipose tissue crosssectional area, TSI time since injury, $V A T_{C S A}$ visceral adipose tissue cross-sectional area

Missing data: ${ }^{\mathrm{a}} n=35,{ }^{\mathrm{b}} n=30,{ }^{\mathrm{c}} n=27$. $* P<0.05$ fat-free mass for total body, trunk, and legs. DXA scans were performed after elevation of the lower extremities for at least $20 \mathrm{~min}$. Body composition and DXA measurements were determined using a Lunar Prodigy Advance bone densitometer (Lunar DPX, Madison, WI, USA). Specific anatomical regions were manually determined by a DXA trained researcher by placing region of interest lines using encore software [19]. The trunk region consisted of the neck, chest, abdominal, and pelvic areas. Lean mass and total body $\%$ fat mass were calculated after excluding the bone tissue. Precision of total and regional body composition compartments have been recently established in men 
with SCI [19]. For the short-term precision assessment, the RMS-CV\% for legs, trunk, gynoid regions, and total body were $2.7,3.8,6.5,5.8$, and $2.3 \%$, respectively [19].

\section{Magnetic resonance imaging}

Magnetic resonance images (MRI) were captured for each participant using a General Electric Signa 1.5-T MRI (fast spin-echo sequence: axial in-phase/out-phase, repetition time: $140 \mathrm{~ms}$, echo time: 4.3 (in-phase), $2 \mathrm{~ms}$ (out-phase), field of view: $42 \mathrm{~cm}$, matrix size: $256 \times 256$, number of excitations: 1, and acquisition time: $2 \mathrm{~min}$ ) and abdominal coil $[15,16,18]$. For the VAT and subcutaneous adipose tissue (SAT) analysis, transverse images were captured between the xiphoid process to the femoral heads, each with a slice thickness of $0.8 \mathrm{~cm}$ and inter-slice space of $1.2 \mathrm{~cm}$. The participants were asked to inhale deeply and hold their breath for $20 \mathrm{~s}$ to prevent breathing artifact. Additionally, for thigh imaging, a body array flex coil was used to collect trans-axial images, $0.8 \mathrm{~cm}$ thick and $1.6 \mathrm{~cm}$ apart. The knees and feet were strapped together to attain a neutral supine position of the lower extremities to prevent involuntary muscle spasms $[15,16,18]$.

Specialized imaging software was used to analyze MRI images (Win Vessel 2, Ronald Meyer, MSU, MI, USA). This software segmented the selected MRI images based on signal intensity into fat, muscle, and bone. Regions of interest were manually traced by an examiner to quantify total trunk CSA, $\mathrm{VAT}_{\mathrm{CSA}}$ and $\mathrm{SAT}_{\mathrm{CSA}}$. The number of pixels contained within the traced region was then multiplied by the matrix size to measure CSA $\left(\mathrm{cm}^{2}\right)$. The ratio of VAT:SAT was then calculated. For each participant, 20-32 multi-axial images were analyzed and averaged based on the length of the trunk. Consistency was maintained among the participants using anatomical landmarks throughout each image sequence. Images extended proximally to include the upper lobes of the two kidneys, and distally to the femoral heads. The coefficients of variability for measuring the total trunk CSA, VAT $_{\mathrm{CSA}}$ and $\mathrm{SAT}_{\mathrm{CSA}}$ were less than $0.3,2.1$. and $1.2 \%$, respectively.

To determine thigh skeletal muscle CSA and \% IMF, the outer perimeter of the thigh muscle group was traced, and the pixel signal intensity within this region was determined automatically. A bimodal histogram of two peaks was then plotted to distinguish between muscle and IMF pixels. The amount of IMF within the muscle CSA was then calculated using the midpoint of the two peaks [20].

\section{Cardiometabolic profile}

After a $10-12 \mathrm{~h}$ overnight fast, blood samples $(\sim 4 \mathrm{~mL})$ were collected to measure triglycerides (TG) and glycated hemoglobin $(\mathrm{HbAlc})$ after inserting a Teflon catheter into an antecubital vein of one arm. After allowing the blood sample to clot for $30 \mathrm{~min}$, it was then centrifuged for $10 \mathrm{~min}$ at 3000 RPM and sent for analysis as previously described [18] using commercially available colorimetric assays (Sigma, Wako Chemicals US, Richmond, VA; and Thermo DMA, Roche, Minneapolis, MN, respectively).

Each participant was then received an intravenous glucose tolerance test (IVGTT). After participants fasted overnight, an intravenous line was placed to facilitate blood sampling and the infusion of glucose. For a total of $180 \mathrm{~min}$, blood samples were briefly drawn at specified time intervals of $1,2,5,10$, and $20 \mathrm{~min}$. At time 0 , glucose $(0.3 \mathrm{~g} / \mathrm{kg})$ was injected. At time 10 , insulin $(0.02 \mathrm{U} / \mathrm{kg})$ was then injected. Using standard methods, fasting lipid profiles were measured before the glucose injection. The Auto Analyzer glucose oxidase method was used to measure plasma glucose, and a commercial radioimmunoassay was used to measure plasma insulin concentration. Plasma insulin concentration was quantified in duplicates by colorimetric enzyme-linked immunosorbent assay (ELISA; Alpco Diagnostics, Salem, NH, USA). To briefly summarize, the ELISA is a sandwich type immunoassay. The standards, controls and samples were placed in a 96-well microplate after it was coated with a monoclonal antibody which is specific for insulin. Detection Antibody was added and the microplate was incubated on a microplate shaker (700-900 rpm). A second incubation was then conducted after washing the wells. Lastly, chemiluminescent substrate was added and a luminescence plate reader was used to read the microplate after $5 \mathrm{~min}$. The amount of serum insulin in the sample was directly proportional to the intensity of the light generated.

Glucose effectiveness $\left(S_{g}\right)$ and insulin sensitivity $\left(S_{i}\right)$, were measured using the MinMod software (MinMod Inc., Pasadena, CA). Using this software, the glucose disposal rate per unit of endogenous insulin per unit time and glucose-mediated glucose disposal rate were then calculated by using a least-squares fitting of the temporal pattern of insulin and glucose throughout the IVGTT [18].

\section{Testosterone}

Testosterone measurements were performed at Virginia Commonwealth University Health Clinical Laboratories after a $10-12 \mathrm{~h}$ fast. Liquid chromatography was used to measure total serum $\mathrm{T}$, with isotope dilution mass spectrometry detection after supported liquid extraction [21]. The amount of testosterone in each sample was calculated from a linear plot generated by purified testosterone standards ranging from 2.5 to $5000 \mathrm{ng} / \mathrm{dL}$. Inter-assay standard accuracy and precision ranged from 1.6-10.6\%. A harmonized normal range of serum $\mathrm{T}$ has been established for 
Table 2 Participants' lipid profile separated based on tertile classifications with each level of serum testosterone

\begin{tabular}{|c|c|c|c|}
\hline & $\begin{array}{l}\text { Low Range Testosterone } \\
(\leq 400 \mathrm{ng} / \mathrm{dL}) \\
(n=12)\end{array}$ & $\begin{array}{l}\text { Mid-Normal Range Testosterone } \\
(401-544 \mathrm{ng} / \mathrm{dL}) \\
(n=12)\end{array}$ & $\begin{array}{l}\text { Normal Range Testosterone } \\
(\geq 555 \mathrm{ng} / \mathrm{dL}) \\
(n=12)\end{array}$ \\
\hline Testosterone (ng/dL) & $288.8 \pm 84.9(141-400)$ & $461.0 \pm 52.5(401-544)$ & $648.0 \pm 53.5^{*}(586-751)$ \\
\hline $\begin{array}{l}\text { **Able-bodied population } \\
\text { percentile [22] }\end{array}$ & $2.5-25 \%$ & $10-50 \%$ & $50-90 \%$ \\
\hline $\mathrm{TG}(\mathrm{mg} / \mathrm{dL})^{\mathrm{a}}$ & $124.6 \pm 55.5$ & $102.2 \pm 44.8$ & $80.2 \pm 28.0^{*}$ \\
\hline $\operatorname{HbA1c}(\%)^{\mathrm{a}}$ & $5.9 \pm 0.54$ & $5.3 \pm 0.31$ & $5.3 \pm 0.24^{*}$ \\
\hline Fasting glucose $(\mathrm{mg} / \mathrm{dL})^{\mathrm{a}}$ & $106.5 \pm 20.5$ & $88.7 \pm 9.2$ & $83.3 \pm 5.9^{*}$ \\
\hline Fasting insulin $(\mu \mathrm{U} / \mathrm{mL})^{\mathrm{b}}$ & $5.3 \pm 3.0$ & $3.4 \pm 1.9$ & $2.2 \pm 0.86$ \\
\hline $\mathrm{S}_{\mathrm{i}}\left[(\mathrm{mU} / \mathrm{L})^{-1} \min ^{-1}\right]^{\mathrm{c}}$ & $3.5 \pm 3.5$ & $8.53 \pm 4.79$ & $12.3 \pm 7.0$ \\
\hline
\end{tabular}

$H b A 1 c$ glycated hemoglobin, $S_{i}$ insulin sensitivity, $T G$ triglycerides

Missing data: ${ }^{\mathrm{a}} n=35,{ }^{\mathrm{b}} n=34,{ }^{\mathrm{c}} n=29 ; * P<0.05$. **. Able-bodied population percentiles were retrieved from Travison et al. [22]. for the purpose of the comparisons for the healthy non-obese men. Data are presented as mean $\pm \mathrm{SD}$

healthy non-obese men 19-39 years old as $264-916 \mathrm{ng} / \mathrm{dL}$ [22].

\section{Statistical analysis}

All data were primarily checked for normality using Shapiro-Wilk tests. Data that were not normally distributed were log-transformed prior to statistical analysis. Participants were placed into tertiles (low, mid-normal, and normal range) based on their serum $T$ levels to evenly stratify our groups $(n=12)$. One-way analysis of variance (ANOVA) was then used to examine the effects of different serum $\mathrm{T}$ levels on body composition and cardiometabolic variables. Pearson's correlations were used to examine the relationships between serum $\mathrm{T}$ levels and both body composition compartments and cardiometabolic variables. Age, TSI, LOI, and BMI were run against serum $\mathrm{T}$ to determine potential covariates. Also, we have accounted for total body fat mass, total body $\%$ fat mass and $\mathrm{VAT}_{\mathrm{CSA}}$ as covariates. The data are presented as mean \pm standard deviation (SD). Statistical significance was set at $P<0.05$. Statistical analysis was completed using IBM-SPSS (version 24.0, SPSS, Chicago, IL, USA).

\section{Results}

The mean values for demographic, anthropometric, MRI, and DXA measurements based on tertile groups for levels of serum $\mathrm{T}$ are presented in Table 1. Serum $\mathrm{T}$ and lipid profiles are compartmentalized into tertile classifications and presented in Table 2 as average values. It should be noted that there were no significant correlations between serum $\mathrm{T}$ levels and age, LOI or TSI, and the serum $\mathrm{T}$ subgroups did not differ with respect to these variables. Accounting for age, TSI and LOI as individual covariates did not influence the correlations between serum $\mathrm{T}$ and any other dependent variables except for VAT:SAT ratio $(r=$ $-0.17, P>0.05$ ); after accounting for LOI.

Serum T was negatively correlated with BMI ( $r=-0.45$, $P=0.006$ ). Table 3 displays Pearson's $r$ and partial correlation coefficients between serum $\mathrm{T}$ and cardiometabolic risk factors after accounting for BMI, total body fat mass, total body \% fat mass and VAT as covariates.

\section{Body composition}

\section{Anthropometrics}

Supine $(\mathrm{F}(2,35)=4.213 ; P=0.02)$ and seated $(\mathrm{F}(2,35)=$ $3.54 ; P=0.02) \mathrm{WC}$ were significantly different among men with different levels of serum $\mathrm{T}$ (Table 1). Pairwise comparisons revealed that men with normal range serum $\mathrm{T}$ had 15 and $12 \%$ smaller supine $(P=0.02)$ and seated $(P=0.03)$ WC, respectively, than those with low range serum $\mathrm{T}$. Serum $\mathrm{T}$ level was negatively related to both supine $(r=$ $-0.44, P=0.007)$ and seated $(r=-0.42, P=0.01) \mathrm{WC}$. These relationships were no longer significant after accounting for BMI or total fat mass and $\mathrm{VAT}_{\mathrm{CSA}}$ as covariates.

Supine $(\mathrm{F}(2,35)=4.578 ; P=0.02)$ and seated $(\mathrm{F}(2,35)$ $=5.91 ; P=0.006)$ abdominal circumference $(\mathrm{AC})$ were significantly different among men with different levels of serum $\mathrm{T}$ (Table 1). Pairwise comparisons revealed that men with normal range serum $\mathrm{T}$ had 17 and $18 \%$ smaller supine $(P=0.02)$ and seated $(P=0.005) \mathrm{AC}$, respectively, than those with low range serum T. Serum $\mathrm{T}$ level was negatively related to both supine $(r=-0.49, P=0.002)$ and seated $(r=-0.54, \quad P=0.0007) \quad$ AC. However after accounting for BMI or total fat mass and $\mathrm{VAT}_{\mathrm{CSA}}$ (Table 3), the relationships between serum $\mathrm{T}$ and supine $\mathrm{AC}$ were no longer significant and trends were noted between serum $\mathrm{T}$ 
Table 3 Pearson's correlation coefficients and partial correlations with adjustments for BMI, \%body fat, and $\mathrm{VAT}_{\mathrm{CSA}}$ as individual covariates between serum testosterone and cardiometabolic risk factors

\begin{tabular}{|c|c|c|c|c|c|}
\hline Outcome & No covariates & BMI & Body fat $(\%)$ & Body fat (g) & $\operatorname{VAT}_{\mathrm{CSA}}\left(\mathrm{cm}^{2}\right)$ \\
\hline \multicolumn{6}{|l|}{ Anthropometric Measurements } \\
\hline Supine WC & $-0.44 * *$ & -0.13 & -0.90 & -0.13 & 0.08 \\
\hline Seated WC & $-0.42^{*}$ & -0.08 & -0.12 & -0.13 & 0.16 \\
\hline Supine AC & $-0.49 * *$ & -0.23 & -0.17 & -0.25 & 0.03 \\
\hline Seated AC & $-0.54 * * *$ & -0.33 & -0.27 & -0.36 & -0.03 \\
\hline \multicolumn{6}{|l|}{ DXA outcomes } \\
\hline \multicolumn{6}{|l|}{ Total } \\
\hline Fat mass $(\%)$ & $-0.48 * *$ & -0.24 & - & -0.24 & -0.08 \\
\hline Fat mass $(\mathrm{g})$ & $-0.44 * *$ & -0.11 & 0.08 & - & -0.002 \\
\hline Lean mass (g) & 0.08 & $0.35^{*}$ & 0.08 & 0.21 & 0.25 \\
\hline \multicolumn{6}{|l|}{ Trunk } \\
\hline Fat mass $(\%)$ & $-0.45^{* *}$ & -0.17 & -0.02 & -0.15 & 0.06 \\
\hline Fat mass (g) & $-0.46^{* *}$ & -0.16 & -0.03 & -0.18 & 0.08 \\
\hline Lean mass (g) & -0.02 & 0.28 & 0.0002 & 0.11 & 0.19 \\
\hline \multicolumn{6}{|l|}{ Legs } \\
\hline Fat mass $(\%)$ & $-0.39 *$ & -0.16 & 0.18 & -0.02 & -0.16 \\
\hline Fat mass $(\mathrm{g})$ & -0.32 & 0.02 & 0.18 & -0.20 & 0.02 \\
\hline Lean mass (g) & 0.22 & $0.38 *$ & 0.23 & 0.32 & 0.30 \\
\hline \multicolumn{6}{|l|}{ MRI outcomes } \\
\hline $\operatorname{VAT}\left(\mathrm{cm}^{2}\right)$ & $-0.56 * *$ & $-0.43^{*}$ & -0.35 & -0.43 & - \\
\hline VAT:SAT & $-0.40^{*}$ & $-0.38 *$ & -0.33 & -0.38 & 0.03 \\
\hline Absolute muscle CSA $\left(\mathrm{cm}^{2}\right)$ & 0.34 & $0.40^{*}$ & 0.23 & 0.32 & 0.18 \\
\hline $\operatorname{IMF}(\%)$ & $-0.41^{*}$ & -0.27 & -0.16 & -0.26 & -0.06 \\
\hline \multicolumn{6}{|l|}{ Carbohydrate Profile } \\
\hline HbA1C (\%) & $-0.39 *$ & $-0.35^{*}$ & $-0.35^{*}$ & -0.39 & -0.16 \\
\hline Fasting glucose (mg/dL) & $-0.46^{* *}$ & $-0.41^{*}$ & $-0.44 * *$ & $-0.45 * *$ & -0.25 \\
\hline Fasting Insulin (mg/dL) & $-0.42^{*}$ & $-0.41 *$ & -0.28 & -0.31 & -0.19 \\
\hline $\mathrm{S}_{\mathrm{i}}\left[(\mathrm{mU} / \mathrm{L})^{-1} \mathrm{~min}^{-1}\right]$ & $0.45 *$ & $0.40 *$ & 0.37 & 0.39 & 0.31 \\
\hline \multicolumn{6}{|l|}{ Lipid Profile } \\
\hline TG (mg/dL) & $-0.36^{*}$ & -0.23 & -0.23 & -0.25 & -0.17 \\
\hline
\end{tabular}

$A C$ abdominal circumference, $B M I$ body mass index, CSA cross-sectional area, DXA dual-energy X-ray absorptiometry, $H b A l C$ glycated hemoglobin, $S_{i}$ insulin sensitivity, $I M F$ intramuscular fat, $N / A$ not available, $S A T$ subcutaneous adipose tissue, $T G$ triglycerides, $V A T$ visceral adipose tissue, $W C$ waist circumference $* P<0.05 ; * * P<0.01$; $* * * P<0.001$; -, variable cannot be assessed and seated AC ( $r=-0.27$ to $-0.36, P<0.09$; Table 3$)$ but not for $\operatorname{VAT}_{\mathrm{CSA}}$.

\section{Dual-energy X-ray absorptiometry}

Total body $\%$ fat mass $(\mathrm{F}(2,35)=3.54, P=0.04)$ was significantly different among men with different levels of $\mathrm{T}$ (Table 1). Pairwise comparisons revealed that men with normal range serum $\mathrm{T}$ had $9.6 \%$ lower total body $\%$ fat mass $(P=0.04)$ compared to those with low range serum $\mathrm{T}$ (Table 1, Fig. 1).

Trunk $\%$ fat mass $(\mathrm{F}(2,35)=3.54, P=0.03)$ and absolute trunk fat mass $(\mathrm{F}(2,35)=3.804 ; P=0.03)$ were significantly different among men with different levels of $\mathrm{T}$ (Table 1). Pairwise comparisons revealed that men with

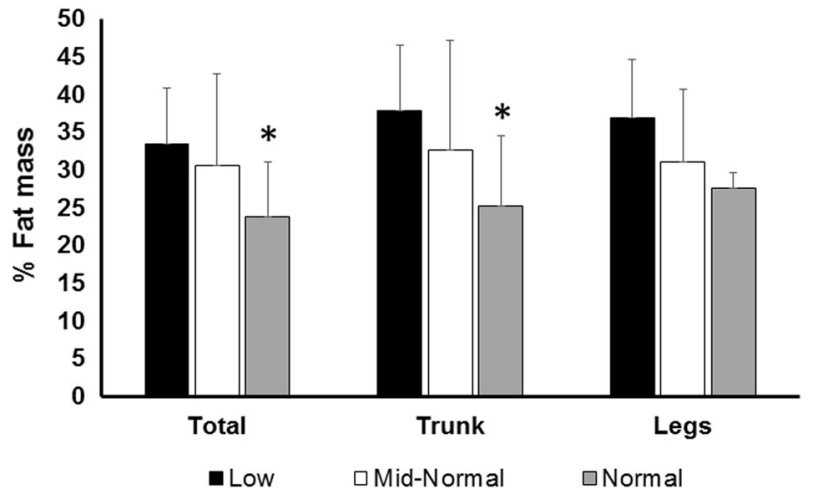

Fig. 1 Mean total, trunk and leg percent fat as analyzed by DXA based on low, mid-normal and normal serum testosterone levels. $* P<0.05$ vs. $\mathrm{T} \leq 400 \mathrm{ng} / \mathrm{dL}$ 
(a)

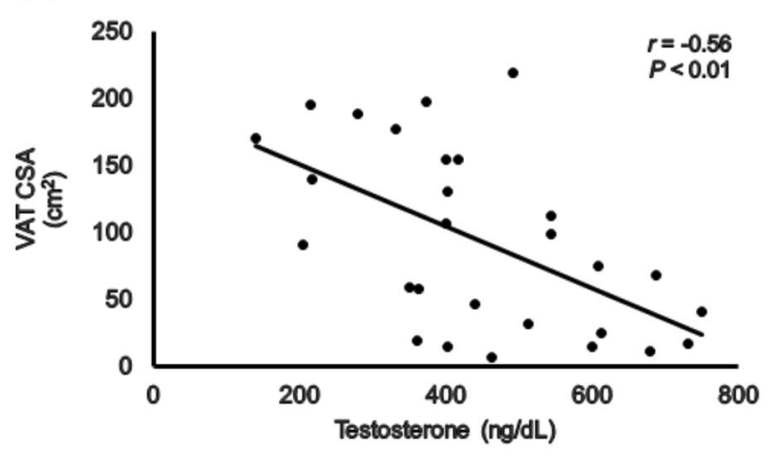

(b)

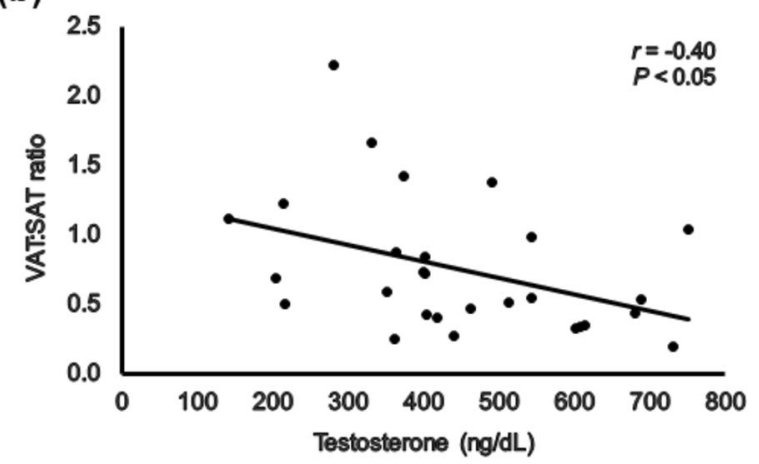

(c)

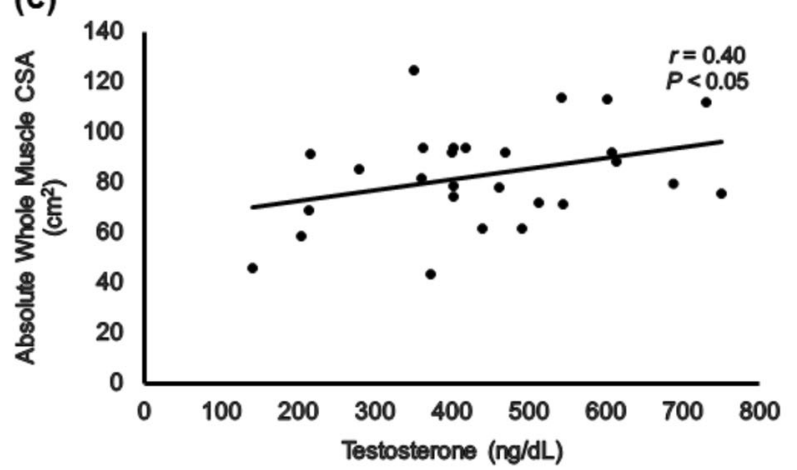

(d)

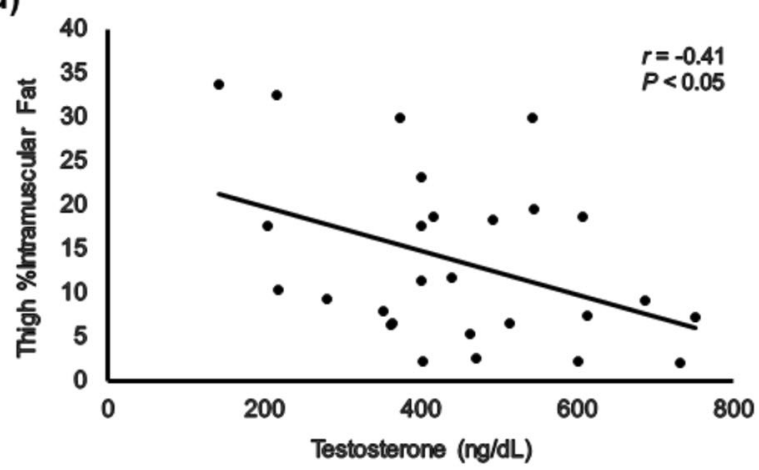

Fig. 2 Relationships between serum testosterone and MRI outcomes including a VAT $\mathrm{VAS}_{\mathrm{CSA}}, \mathbf{b}$ VAT:SAT ratio, $\mathbf{c}$ absolute whole thigh muscle CSA and $\mathbf{d}$ thigh \%IMF. The $r$ and $P$ values presented in relationship (c) are those after accounting for BMI as a covariate

normal range serum T had 12.7 and $45 \%$ lower trunk \%fat mass $(P=0.04$; Fig. 1$)$ and absolute trunk fat mass $(P=$ $0.03)$, respectively, compared to men with low range serum $\mathrm{T}$. There were no significant differences in leg $\%$ fat mass (Fig. 1), leg fat mass or leg lean mass among men with different levels of serum $\mathrm{T}$.

\section{Magnetic resonance imaging}

$\operatorname{VAT}_{\mathrm{CSA}}(\mathrm{F}(2,27)=5.05 ; P=0.014)$ and VAT:SAT ratio $(\mathrm{F}(2,27)=3.99 ; \quad P=0.03) \quad$ were significantly different among men with different levels of serum $\mathrm{T}$ (Table 1). Pairwise comparisons revealed that men with normal range serum $\mathrm{T}$ had 72 and $55 \%$ lower $\operatorname{VAT}_{\mathrm{CSA}}(P=0.01)$ and VAT:SAT ratio $(P=0.03)$, respectively, compared to men with low range serum $\mathrm{T}$. Serum $\mathrm{T}$ was negatively related to VAT $_{\text {CSA }}$ and VAT:SAT (Fig. 2a, b, respectively), even after accounting for BMI $(r=-0.43, P=0.02 ; r=-0.38, P<$ 0.05 , respectively).

Serum $\mathrm{T}$ showed a positive trend with absolute whole thigh muscle CSA $(r=0.34, P=0.08)$. However, when BMI was accounted for, the relationship attained a statistical significance (Fig. 2c; $r=0.40, P<0.05$ ). Serum $\mathrm{T}$ was negatively related with \%IMF (Fig. 2d); however, after accounting for BMI, total body fat mass or $\mathrm{VAT}_{\mathrm{CSA}}$, the relationships were no longer significant.

\section{Cardiometabolic profile}

Serum TG levels $(\mathrm{F}(2,35)=3.97 ; P=0.03)$ were significantly different among men with different levels of serum T. Pairwise comparisons revealed that men with normal range serum $\mathrm{T}$ level had $41 \%$ less serum TG $(P=$ 0.03 ) compared to men with low range serum $\mathrm{T}$ level (Table 2). Serum $\mathrm{T}$ was negatively related to serum TG (Fig. 3a), however, the relationships were no longer significant after accounting for BMI, total body fat mass or $\mathrm{VAT}_{\mathrm{CSA}}$. Serum $\mathrm{T}$ was negatively related to HbA1c $(r=$ $-0.39, P=0.02)$, even after accounting for BMI $(r=$ $-0.35, P=0.04)$.

Fasting glucose $(\mathrm{F}(2,34)=3.77 ; P=0.03)$ was significantly different among men with different levels of serum T. Pairwise comparisons revealed that men with normal range serum $\mathrm{T}$ had $15 \%$ lower fasting glucose $(P=$ 0.03 ) levels than men with low range serum $\mathrm{T}$ (Table 2). Serum $\mathrm{T}$ was negatively related to fasting glucose levels (Fig. 3b), even after accounting for BMI $(r=-0.41, P=$ $0.02), \%$ body fat $(r=-0.44, P<0.01)$ and body fat $(r=$ $-0.45, P<0.01)$ and did not attain significance after accounting for $\operatorname{VAT}_{\mathrm{CSA}}$ (Table 3). Serum $\mathrm{T}$ was negatively related to fasting insulin (Fig. 3c) and positively related to insulin sensitivity (Fig. 3d), and these relationships remained statistically significant after accounting for BMI 

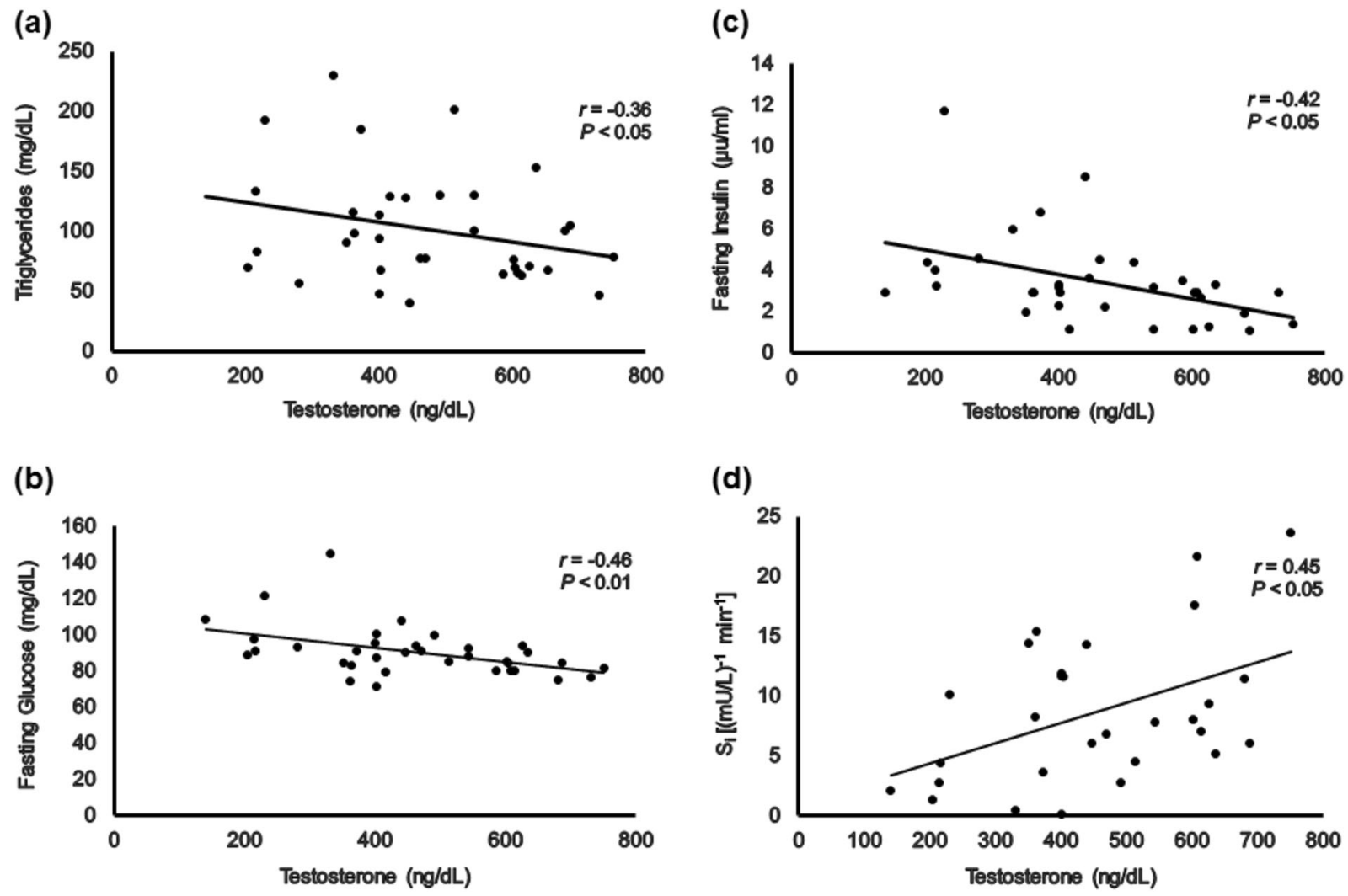

Fig. 3 Relationships between serum testosterone and a serum TG, b fasting glucose, $\mathbf{c}$ fasting insulin and $\mathbf{d}$ insulin sensitivity ( $\mathrm{S}_{\mathrm{i}}$ )

( $r=0.40, P=0.03 ; r=-0.41, P=0.02$, respectively), but not after accounting for total body fat mass or $\operatorname{VAT}_{\mathrm{CSA}}$ (Table 3).

\section{Discussion}

The findings demonstrated that multiple indicators of cardiometabolic health and body composition variables are associated with serum $\mathrm{T}$ levels in men with motor complete SCI. The low range serum $\mathrm{T}$ group had $9.6 \%$ greater total and $12.7 \%$ greater trunk $\%$ fat mass compared to normal range serum $\mathrm{T}$ group. Additionally, $\mathrm{VAT}_{\mathrm{CSA}}$ and VAT:SAT ratio were 72 and $55 \%$, respectively, greater in low range compared to normal range serum $\mathrm{T}$ group. Serum $\mathrm{T}$ was positively related to whole thigh muscle CSA after controlling for BMI, and was negatively related to biomarkers of carbohydrate and lipid metabolism including fasting glucose, insulin, $\mathrm{HbA1c}$, TG, and positively related to insulin sensitivity. Since BMI was significantly correlated with serum $\mathrm{T}$, it was used as a covariate to account for variance in body size among different participants. Despite the well-recognized limitation that BMI underestimates percentage fat mass [23], BMI is still used as a surrogate for whole body fat mass, which in turn is associated negatively with serum $\mathrm{T}$ levels. To account for such limitation in persons with SCI [23], detailed body composition assessments using DXA and MRI were conducted to provide better insights on the associations between serum T-levels and regional adiposity compared to other surrogate indices. Finally, the use of $\mathrm{VAT}_{\mathrm{CSA}}$ a covariate masked all significant associations between serum $\mathrm{T}$ levels and cardiometabolic health variables.

Previous work noted discrepancies between serum $T$ levels and BMI. Barbonetti et al. showed that in 51 persons with different AIS classification A-D as BMI increased serum $\mathrm{T}$ level decreased. The authors showed that persons with lower BMI have serum T level greater than $300 \mathrm{ng} / \mathrm{dL}$ compared to those with $\mathrm{BMI}>25.26 \mathrm{~kg} / \mathrm{m}^{2}$ [12]. In contrast, a recent study showed that BMI was not an influential factor in determining the serum $\mathrm{T}$ level in persons with SCI, whereas total body $\%$ fat mass was an accurate determinant of circulating serum $\mathrm{T}$ level [13]. In the current study, persons with normal T-level $(>555 \mathrm{ng} / \mathrm{dl}$ ) had an average BMI of $21.5 \mathrm{~kg} / \mathrm{m}^{2}$; which was significantly lower than those with low-T level (Table 1). Compared to other published reports [11, 13], our population has lower BMI and WC because they were a relatively younger aged group. Considering the work of Sullivan et al. [13], we have also accounted for total body fat, total body $\%$ fat mass, and $\mathrm{VAT}_{\mathrm{CSA}}$ as covariates. It is interest to note that the relationships between serum T-level and markers of 
carbohydrate metabolism was unaffected by either total body or body $\%$ fat mass. This may suggest the direct action of T-levels on carbohydrate metabolism independent of total body fat mass. After accounting for $\mathrm{VAT}_{\mathrm{CSA}}$, the relationships between serum $\mathrm{T}$ levels and cardiometabolic risk factors were no longer significant; suggesting that VAT plays an influential role in establishing these relationships compared to whole body fat mass. This may provide credence to our current hypothesis that regional assessments of body composition are more influential to the overall cardiometabolic profile in this population.

Age was not a predictor of serum $\mathrm{T}$ and was not different among the subgroups. This is contrary to previous work [6], Bauman et al. demonstrated serum $\mathrm{T}$ decreases as persons with SCI age [6]. However, Bauman et al. study's mean age group was 48 years old with age range from 21 to 78 years compared to the current mean age of 37 years old with age range 18 to 61 years. Thus, the current cohort was younger in age and relatively homogeneous which could explain the discrepancy between both studies.

\section{Body composition}

Positive relationships were found between serum $\mathrm{T}$ and lean mass analyzed by DXA and absolute whole thigh skeletal muscle CSA analyzed by MRI only after accounting for BMI. These findings suggest that serum $\mathrm{T}$ exerts direct effects on lean mass and muscle CSA after considering the variability in body size among our participants. Previous findings demonstrated that serum $\mathrm{T}$ is positively correlated with total trunk muscle CSA in men with SCI [24]. The positive association between serum $\mathrm{T}$ and either muscle CSA or lean mass may provide a support for the rationale that administering testosterone replacement therapy (TRT) may attenuate or restore the loss in lean mass in persons with SCI. Administering topical TRT in persons with SCI has shown improvements in total lean body mass $(0.7-2.7$ $\mathrm{kg}$ ); even more than TRT studies on elderly hypogonadal men [25]. A recent case report supports the hypothesis that TRT invokes skeletal muscle hypertrophy without the use of exercise intervention [26]. Overall, several studies suggested that TRT may help improve lean mass within the first three to 6 months of therapy [25]. Bauman et al. reported the safety of using TRT in hypogonadal men with SCI who were followed over the course of 1 year and showed increases in total and regional lean tissue mass as well as basal metabolic rate [27].

The present study shows evidence that individuals with low serum $\mathrm{T}$ concentrations have greater $\mathrm{VAT}_{\mathrm{CSA}}$ compared to those with normal range serum T. Additionally, thigh \% IMF was negatively correlated with serum $\mathrm{T}$ levels. The negative association of ectopic adiposity on metabolic profile in men with SCI is well established [3-5, 15]. One hypothesis is that serum $\mathrm{T}$ and adiposity may be linked through the hypogonadism-obesity-adipocytokine cycle [28]. Adipose tissue produces aromatase which helps metabolize T to estradiol [28]. VAT has higher metabolic activity and contains a greater number of androgen receptors; both may lead to a decrease in the circulating $\mathrm{T}$. The negative relationship between serum $\mathrm{T}$ concentrations and $\mathrm{VAT}_{\mathrm{CSA}}$ in this study contributes to this hypothesis. A decrease in serum $\mathrm{T}$ may impair lipoprotein lipases' action resulting in an increase in VAT. Additionally, VAT produces leptin which can directly inhibit $\mathrm{T}$ production from the testes [29]. Although numerous studies have shown to be inconclusive on the effects of TRT on fat mass, one study showed that participants receiving TRT gained an average of $1.2 \mathrm{~kg}$ less fat mass over 12 months when compared to the control group [25]. TRT may be beneficial in hypogonadal men with SCI as evident by decreasing accumulation of fat mass, $\mathrm{VAT}_{\mathrm{CSA}}$ and thigh \% IMF.

\section{Cardiometabolic profile}

Men with low serum $\mathrm{T}$ have higher fasting serum insulin, glucose levels, and lower insulin sensitivity. Insulin resistance is commonly associated with increases in $\mathrm{VAT}_{\mathrm{CSA}}$ in able-bodied persons and individuals with SCI, and is a preceding factor of obesity, type 2 diabetes mellitus and metabolic syndrome [3-5, 15]. A previous meta-analysis suggested that serum $\mathrm{T}$ were lower in persons with type 2 diabetes mellitus and men with normal $\mathrm{T}$ levels had a $42 \%$ lower risks of developing type 2 diabetes mellitus [30]. The findings remained significant even after adjustment for obesity as determined by BMI and waist to hip ratio among men with different T-levels [30]. This supports our findings that serum $\mathrm{T}$ is negatively related to fasting glucose and HbA1c (\%) independent of obesity and body fatness in men with SCI (Table 3).

Testosterone may also be linked to metabolic risk factors via its anabolic effects on mitochondrial biogenesis [31]. One study investigated the hypothesis that impairment of mitochondrial function in skeletal muscle tissue may be the mechanism by which low $\mathrm{T}$ is linked to insulin resistance and type 2 diabetes [31]. Increased mitochondrial function is linked to increased lean mass, decreased adipose tissue and improvement in both carbohydrate and lipid profile in men with motor complete SCI [32]. Testosterone has been shown to induce mitochondrial biogenesis in rats, as well as increase the expression of peroxisome proliferator-activated receptor-c coactivator-1a, ATP5B, and Cox4 in skeletal muscle [33]. Combined with previous findings [33], the current results suggest that an increase in serum $\mathrm{T}$ may attenuate loss in muscle mass, decrease ectopic adiposity and improve cardiometabolic profile by possibly inducing mitochondrial biogenesis. 


\section{Limitations}

The amount of persons living with SCI is relatively small, with approximately 18,000 new cases per year. Considering barriers associated with SCI [34], recruiting within a smallsized group can be challenging, especially volunteers with motor complete SCI, which is a subgroup of the entire SCI population. Persons with motor complete SCI were included to control for variability in body composition and metabolic profile, which may influence the association with serum $\mathrm{T}$. Moreover, the three subgroups were not different with respect to age, TSI and LOI; suggesting the need for larger sample size studies to examine how these variables may influence the relationships between serum $\mathrm{T}$ level and cardiometabolic risk factors. It is also difficult to generalize the findings to persons with incomplete SCI (AIS C and D) and separate investigations are warranted to examine the association between serum $\mathrm{T}$ and regional body composition in this cohort.

The data in this study are cross-sectional and are compiled from two separate studies using the same methods of measuring body composition and metabolic profiles. Due to the data being compiled from a cross-sectional design causality cannot be established. To account for the lack of control group, we have used published data (Table 2) to provide able-bodied reference norms for the enrolled participants [22].

Although the Endocrine Society defines hypogonadism as $\mathrm{T}$ levels below $300 \mathrm{ng} / \mathrm{dL}$, we chose to stratify our subjects by tertiles to evenly stratify our data. Furthermore, we measured total serum $\mathrm{T}$ levels without measuring free or bioavailable $\mathrm{T}$ concentrations. Future studies should measure sex-hormone binding globulin levels and address the impact of bioavailable or free circulating $\mathrm{T}$ on body composition and metabolic profile in individuals with SCI.

\section{Conclusion}

Men with lower serum $\mathrm{T}$ have a more unfavorable body composition and cardiometabolic profile after SCI. Using DXA and MRI measures of body composition, men with lower serum $\mathrm{T}$ levels have more total body fat mass, and greater $\mathrm{VAT}_{\mathrm{CSA}}$ when compared to the participants with high serum $\mathrm{T}$. The results highlight the significance of measuring regional adiposity on the determined relationships between serum $\mathrm{T}$ and cardiometabolic risk factors. Additionally, men with low serum $\mathrm{T}$ also have higher circulating serum TG, higher fasting plasma glucose and insulin levels. Moreover, serum $\mathrm{T}$ was associated with better insulin sensitivity. The results suggest that the use of TRT may be a potential strategy in attenuating adverse body composition changes and cardiometabolic consequences in men with chronic SCI.
Acknowledgements We would like to thank all the study participants for their time and effort. We would also like to thank Hunter Holmes McGuire Research Institute and Spinal Cord Injury Services and Disorders for providing the environment to conduct clinical human research trials. We would like to thank the Radiology Department and MRI technicians for providing the time and effort in collecting the scans.

Funding The work is supported by the Department of Veteran Affairs, Veteran Health Administration, Rehabilitation Research and Development Service (B7867-W) and Department of Defense (DoD) Congressionally Directed Medical Research Program (CDRMP: W81XWH-14-SCIRP-CTA) grants.

Author contributions S.M.A. was responsible for data capturing, extracting and data analysis, conducting literature search, manuscript drafting and writing, presentation of figures, revising the work and updating reference lists and creating tables. R.M.S. was responsible for data analysis, manuscript drafting and writing, conducting literature search, manuscript drafting and writing, presentation of figures and creating tables. R.S.G. was responsible for designing and conceptualize the protocol, reviewing analyzed data, providing feedback concerning writing and help interpreting the results of the study. R.A. A. was responsible for designing and conceptualize the protocol, reviewing analyzed data, providing feedback concerning writing and help interpreting the results of the study. A.S.G. was responsible for designing and conceptualize the protocol, securing funding, reviewing analyzed data, manuscript drafting and writing, interpreting the results of the study, revising and submitting the work.

\section{Compliance with ethical standards}

Conflict of interest The authors declare that they have no conflict of interest.

\section{References}

1. Bauman WA, Spungen AM. Disorders of carbohydrate and lipid metabolism in veterans with paraplegia or quadriplegia: a model of premature aging. Metabolism. 1994;43:749-56.

2. Spungen AM, Wang J, Pierson RN, Bauman WA. Soft tissue body composition differences in monozygotic twins discordant for spinal cord injury. J Appl Physiol. 1985;2000:1310-5.

3. Edwards LA, Bugaresti JM, Buchholz AC. Visceral adipose tissue and the ratio of visceral to subcutaneous adipose tissue are greater in adults with than in those without spinal cord injury, despite matching waist circumferences. Am J Clin Nutr. 2008;87:600-7.

4. Farkas GJ, Gorgey AS, Dolbow DR, Berg AS, Gater DR. The influence of level of spinal cord injury on adipose tissue and its relationship to inflammatory adipokines and cardiometabolic profiles. J Spinal Cord Med. 2018;41:407-15.

5. Gorgey AS, Dolbow DR, Dolbow JD, Khalil RK, Castillo C, Gater DR. Effects of spinal cord injury on body composition and metabolic profile - part I. J Spinal Cord Med. 2014;37:693-702.

6. Wu FC, Tajar A, Pye SR, Silman AJ, Finn JD, O’Neill TW, et al. Hypothalamic-pituitary-testicular axis disruptions in older men are differentially linked to age and modifiable risk factors: the European Male Aging Study. J Clin Endocrinol Metab. 2008;93:2737-45.

7. Lamberts SW, van den Beld AW, van der Lely AJ. The endocrinology of aging. Science. 1997;278:419-24.

8. Maggio M, Lauretani F, Ceda GP. Sex hormones and sarcopenia in older persons. Curr Opin Clin Nutr Metab Care. 2013;16:3-13. 
9. Milanović Z, Pantelić S, Trajković N, Sporiš G, Kostić R, James $\mathrm{N}$. Age-related decrease in physical activity and functional fitness among elderly men and women. Clin Interv Aging. 2013;8:549-56.

10. Stanworth RD, Jones TH. Testosterone for the aging male; current evidence and recommended practice. Clin Interv Aging. 2008;3:25-44.

11. Bauman WA, La Fountaine MF, Spungen AM. Age-related prevalence of low testosterone in men with spinal cord injury. J Spinal Cord Med. 2014;37:32-39.

12. Barbonetti A, Vassallo MR, Pacca F, Cavallo F, Costanzo M, Felzani G, et al. Correlates of low testosterone in men with chronic spinal cord injury. Andrology . 2014;2:721-8.

13. Sullivan SD, Nash MS, Tefara E, Tinsley E, Groah S. Relationship Between Gonadal Function and Cardiometabolic Risk in Young Men With Chronic Spinal CordInjury. PM R. 2017;10:373-81.

14. Mohler ER, Ellenberg SS, Lewis CE, Wenger NK, Budoff MJ, Lewis MR, et al. The Effect of Testosterone on Cardiovascular Biomarkers in the Testosterone Trials. J Clin Endocrinol Metab. 2018;103:681-8.

15. Gorgey AS, Mather KJ, Gater DR. Central adiposity associations to carbohydrate and lipid metabolism in individuals with complete motor spinal cord injury. Metabolism. 2011;60:843-51.

16. Gorgey AS, Mather KJ, Poarch HJ, Gater DR. Influence of motor complete spinal cord injury on visceral and subcutaneous adipose tissue measured by multi-axial magnetic resonance imaging. J Spinal Cord Med. 2011;34:99-109.

17. Gorgey AS, Gater DR. Regional and relative adiposity patterns in relation to carbohydrate and lipid metabolism in men with spinal cord injury. Appl Physiol Nutr Metab. 2011;36:107-14.

18. Gorgey AS, Khalil RE, Gill R, O'Brien LC, Lavis T, Castillo T, et al. Effects of Testosterone and Evoked Resistance Exercise after Spinal Cord Injury (TEREX-SCI): study protocol for a randomised controlled trial. BMJ Open. 2017;7:e014125.

19. Gorgey AS, Cirnigliaro CM, Bauman WA, Adler RA Estimates of the precision of regional and whole body composition by dualenergy x-ray absorptiometry in persons with chronic spinal cord injury. Spinal Cord. 2018;56:987-995.

20. Gorgey AS, Mather KJ, Cupp HR, Gater DR. Effects of resistance training on adiposity and metabolism after spinal cord injury. Med Sci Sports Exerc. 2012;44:165-74.

21. Vermeulen A, Verdonck L, Kaufman JM. A critical evaluation of simple methods for the estimation of free testosterone in serum. $\mathrm{J}$ Clin Endocrinol Metab. 1999;84:3666-72.
22. Travison TG, Vesper HW, Orwoll E, Wu F, Kaufman JM, Wang $Y$, et al. Harmonized reference ranges for circulating testosterone levels in men of four cohort studies in the United States and Europe. J Clin Endocrinol Metab. 2017;102:1161-73.

23. Jones LM, Legge M, Goulding A. Healthy body mass index values often underestimate body fat in men with spinal cord injury. Arch Phys Med Rehabil. 2003;84:1068-71.

24. Abilmona SM, Gorgey AS Associations of the trunk skeletal musculature and dietary intake to biomarkers of cardiometabolic health after spinal cord injury. Clin. Physiol. Funct. Imaging. 2018;38:949-958.

25. Nightingale TE, Moore P, Harman J, Khalil R, Gill RS, Castillo T, et al. Body Composition changes with testosterone replacement therapy following spinal cord Injury and aging. A mini review. $J$. Spinal Cord Med. 2017;1-21.

26. Gorgey AS, Moore PD, Wade RC, Gill RS, Lavis T, Adler RA. Disruption in bone marrow fat may attenuate testosterone action on muscle size after spinal cord injury: a case report. Eur J Phys Rehabil Med. 2017;53:625-9.

27. Bauman WA, Cirnigliaro CM, La Fountaine MF, Jensen AM, Wecht JM, Kirshblum SC, et al. A small-scale clinical trial to determine the safety and efficacy of testosterone replacement therapy in hypogonadal men with spinal cord injury. Horm Metab Res. 2011;43:574-9.

28. Stanworth RD, Jones TH. Testosterone in obesity, metabolic syndrome and type 2 diabetes. Front Horm Res. 2009;37:74-90.

29. Jones $\mathrm{TH}$. Testosterone associations with erectile dysfunction, diabetes and the metabolic syndrome. Eur Urol (Suppl). 2007;6:847-57.

30. Ding EL, Song Y, Malik VS, Liu S. Sex differences of endogenous sex hormones and risk of type 2 diabetes: a systematic review and meta-analysis. JAMA. 2006;295:1288-99.

31. Pitteloud N, Mootha VK, Dwyer AA, Hardin M, Lee H, Eriksson $\mathrm{KE}$, et al. Relationship between testosterone levels, insulin sensitivity, and mitochondrial function in men. Diabetes Care. 2005;28:1636-42.

32. O’Brien LC, Wade RC, Segal L, Chen Q, Savas J, Lesnefsky EJ, et al. Mitochondrial mass and activity as a function of body composition in individuals with spinal cord injury. Physiol. Rep. 2017;5.

33. Usui T, Kajita K, Kajita T, Mori I, Hanamoto T, Ikeda T, et al. Elevated mitochondrial biogenesis in skeletal muscle is associated with testosterone-induced body weight loss in male mice. FEBS Lett. 2014;588:1935-41.

34. Gorgey AS. Exercise awareness and barriers after spinal cord injury. World J Orthop. 2014;5:158-62. 